\title{
El control de constitucionalidad represivo concreto de los tratados internacionales como fuente del derecho interno: Una visión crítica de los roles 1288 y 2789 del Tribunal Constitucional de Chile $^{1}$
}

\author{
The Repressive and Specific Constitutionality Control of the International Treaties as \\ Source of National Law: A Critical View of the Sentences $N^{\circ} 1288$ y $N^{\circ} 2789$ of the \\ Chilean Constitutional Court
}

\section{Manuel Arturo Yáñez Espinoza}

manuelyanez@outlook.es

Egresado de la Facultad de Derecho de la Universidad de Talca. Ayudante de la Cátedra de Derecho Internacional Público. Ha cursado estudios en derechos humanos y ciencia política en la Universidad de Valencia (España).

Resumen: Se estudian y analizan dos resoluciones del Tribunal Constitucional en las cuales se pronuncia sobre la procedencia del recurso de inaplicabilidad por inconstitucionalidad de los tratados internacionales. En el primero de ellos se sustenta la posibilidad de impetrar la acción de inaplicabilidad, en el segundo y sin mayor razonamiento se descarta tal opción. Frente a ello se razona de forma crítica y considerando a los tratados internacionales como fuente del derecho interno, que éstos sí son preceptos legales y sí son objeto de control represivo concreto de constitucionalidad, dejando claro, la eventual posibilidad de la responsabilidad internacional del Estado.

Palabras clave: Tribunal Constitucional, Recurso de inaplicabilidad por inconstitucionalidad, tratados internacionales.

\begin{abstract}
We study and analyze two decisions of the Constitutional Court in which it rules on the merits of the action of unconstitutionality of international treaties. In the first it is based implore the possibility of action of inapplicability, in the second and without further reasoning that option is discarded. It argues against critically and considering international treaties as a source of domestic law, which they themselves are legal provisions and it is subject to specific repressive control of constitutionality, making it clear, the eventual possibility of international responsibility of the State.
\end{abstract}

Keywords: Constitutional Court, Specific Repressive Control of Constitutionality, International Treaties.

1 Comentario jurisprudencial recibido el 04.10.2015 y aceptado el 13.12.2015. 


\section{Planteamiento de la cuestión}

La cuestión que planteo en este comentario ${ }^{2}$ se refiere a la procedencia del control represivo concreto de constitucionalidad de los tratados internacionales considerados como fuente del Derecho Interno, diferenciando sus consecuencias en el Derecho Internacional (efectos).

El Tribunal Constitucional de Chile es el órgano de cierre en la interpretación de la Constitución y órgano jurisdiccional especializado en la materia. A partir de las Bases de la Institucionalidad el principio de Supremacía de la Constitución establecido en el art. 6 y 7 de la Carta Fundamental en conjunto con el de Soberanía Nacional (art. 5.1) impregnan la labor del Tribunal y determinan la juridicidad del ordenamiento jurídico nacional (validez) ${ }^{3}$.

Ya entrando en el asunto, cabe señalar que el Tribunal Constitucional ha establecido en su jurisprudencia dos cuestiones relevantes: 1 . El concepto de precepto legal y 2. El derecho convencional internacional vigente en el orden jurídico interno son preceptos legales ${ }^{4}$ (no nos importa la vigencia en el orden jurídico internacional a efectos del presente comentario, como aclararemos más adelante).

Siendo coherente en esa línea, el Tribunal respecto del control represivo concreto de constitucionalidad en rol 1288 (sede control obligatorio preventivo de constitucionalidad de leyes orgánico constitucionales) señala fundamentalmente que:

a) Los tratados internacionales en cuanto a su vigencia interna se someten a la Constitución. Son inferiores a la Constitución.

b) Asimila parcialmente el Tratado a la ley, y lo considera, desde su ubicación en el ordenamiento jurídico interno como un precepto legal (pues regulan materias de dominio legal).

c) El tratado internacional por el mero acto de la ratificación se incorpora al derecho interno, como precepto legal ${ }^{5}$.

Sentencia Rol 1288-2008 del Tribunal Constitucional, 25 de agosto de 2009; Sentencia Rol 2789-2015 del Tribunal Constitucional, Rol 2789-2015, 25 de marzo de 2015. Sus correspondientes expedientes y el texto completo de las sentencias están disponibles en: www.tribunalconstitucional.cl.

3 Se desprende de la propia jurisprudencia del Tribunal Constitucional: "El control a posteriori de la constitucionalidad de la ley, que puede derivar (...) en la expulsión de un precepto del ordenamiento jurídico positivo, es una competencia que procura regular el correcto funcionamiento y la eficacia del Estado de Derecho, lográndose con ello el fortalecimiento constante de los sistemas de frenos y contrapesos al actuar de los órganos del Estado en forma compatible con aquella división de funciones prevista en los artículos 6 y 7 de la Constitución". Sentencia Rol 681-2006 del Tribunal Constitucional, 26 de marzo de 2006.

4 A modo ejemplar roles: 288, 309, 312 y 346, todos del Tribunal Constitucional. Ver en buscador de sentencias en: www.tribunalconstitucional.cl.

5 Se puede sostener siguiendo la práctica jurisprudencial nacional y lo señalado por los profesores Aldunate y Llanos Mansilla, que el Tratado produce efectos en el derecho interno desde su promulgación y publicación. Sin dichos requisitos el tratado internacional, solo conserva su capacidad original de generar obligaciones en el orden jurídico internacional. Distinción que como veremos cobra gran relevancia y en la cual el Tribunal Constitucional no repara. 
Revista Tribuna Internacional

Volumen $5 \bullet \mathrm{N}^{\circ}$ 9 $・ 2016 \bullet$ pp. 155-161

ISSN 0719-482X (versión en línea)

d) Reconoce la regla de derecho internacional general constitucionalizada por el art. 54 . 1 de la Constitución, que hace referencia al principio consagrado en el art. 27 de la Convención de Viena sobre Derecho de los Tratados.

e) Por tanto, procede la declaratoria de inaplicabilidad, y es inconstitucional al legislador restringir las competencias constitucionales del Tribunal.

Esta sentencia fue criticada por cierto sector de la doctrina internacionalista, pues, principalmente señalaban que: al privar de efectos a un tratado internacional en el orden interno, éste se suspendía, y por tanto, se contrariaba el art. 54. 1 de la Constitución. Más adelante nos pronunciaremos sobre esta crítica.

Pero el Tribunal Constitucional, extrañamente cambia su criterio este año en el rol 2789, paradójicamente, pronunciándose en sala sobre la admisibilidad de un recurso de inaplicabilidad, donde, sin mayor razonamiento señala:

a. "(...) que una norma de un tratado internacional ratificado por Chile no constituye un precepto que tenga rango legal, en términos tales que pueda promoverse a su respecto una acción de inaplicabilidad' (subrayado es del autor).

b. La declaratoria de inaplicabilidad contraría los compromisos internacionales del Estado, refiriéndose al principio pacta sunt servanda consagrado en el art. 27 de la Convención de Viena y la propia Constitución en su art. 54. 1.

En este sentido, aparentemente tenemos dos pronunciamientos vigentes sobre el mismo asunto en la jurisprudencia del Tribunal Constitucional.

\section{Las tesis sobre el Control represivo concreto de los Tratados internacionales como fuente del derecho interno}

\subsection{El Tribunal Constitucional y la irresponsabilidad internacional del Estado}

Esta tesis podría ser formulada de la siguiente manera: El control represivo concreto (acción de inaplicabilidad) respecto de los tratados internacionales vigentes en el orden jurídico interno es resultado del principio de supremacía constitucional en el ámbito interno, en cuanto a sus efectos, se somete el derecho convencional internacional. Y al ejercerlo, no se deroga, modifica, ni suspende el tratado, ni se incurre en responsabilidad internacional.

Hugo Llanos, Teoría y práctica del derecho internacional público, Tomo IV, (Santiago: Editorial Jurídica de Chile, 2011), 140143. Eduardo Aldunate, "La posición de los tratados internacionales en el sistema de fuentes del ordenamiento jurídico chileno a la luz del derecho positivo", Ius et Praxis 16(2) (2010): 185-210. 
Esta tesis es sostenida por el Tribunal Constitucional en el rol 1288, al cual ya nos referimos. Se puede sostener que la Magistratura Constitucional de forma implícita considera que no puede existir responsabilidad internacional al declarar inaplicable un tratado internacional. Ello queda más claro en el voto particular de dicha sentencia, del entonces Ministro Mario Fernández Baeza, quien también de forma implícita resalta el asunto.

\subsection{La intangibilidad de los Tratados Internacionales impide el control represivo en todas sus formas}

Esta tesis es la sostenida por cierto sector de la doctrina internacionalista ${ }^{6}$ y el Tribunal en su reciente fallo rol 2789. Esta tesis se puede formular de la siguiente manera: Los tratados internacionales ingresan al ordenamiento jurídico como fuente heterodoxa a nuestro ordenamiento jurídico, se mantienen como parte del orden jurídico internacional, y así produce sus efectos en el orden jurídico interno, y constitucionalmente el art. 54.1 otorga dicho carácter ${ }^{7}$.

Esto se sostiene en virtud del principio pacta sunt servanda y el principio que indica que no podrá un Estado oponer su derecho interno para incumplir sus obligaciones de Derecho Internacional. Así, en el entendido de quienes sostienen esto, los tratados internacionales son constitucionalmente intangibles para el operador jurídico, y sólo puede limitarse a su aplicación preferente en el orden interno, aun cuando genere efectos contrarios a la Constitución. Así, en la práctica, los tratados internacionales adquieren una fuerza normativa superior a la Carta Suprema.

\section{Una tesis constitucional y realista sobre el asunto}

Las tesis anteriores tienes aspectos positivos y negativos, nada es perfecto. Pero desde el punto de vista constitucional la tesis sostenida en el Rol 1288 es la más adecuada y correcta, con necesarias precisiones. Mientras que la segunda tesis implica un desconocimiento de dos elementos: 1. La naturaleza del orden jurídico internacional y su relación con los ordenamientos jurídicos domésticos y 2. El principio de supremacía constitucional, del cual es garante el Tribunal Constitucional. Por su parte, la primera tesis, tiene una

6 Yanira Zuñiga, "La sentencia Rol 1340 y la sentencia Rol 1288. Una reflexión sobre el (oscuro) rol de los tratados internacionales en el marco del control de constitucionalidad”, en Jurisprudencia Constitucional Destacada, coord. Pablo Marshall (Santiago: Legalpublishing, 2011), 3-17.

7 Así el Prof. Pica criticando el rol 1288 sostiene que “(...) pues abora se declara de manera expresa en la carta fundamental que nunca una ley o cualquier norma de derecho interno podrá modificar lo dispuesto en un tratado". Rodrigo Pica, "Control de constitucionalidad y tratados internacionales: ¿objeto o parámetro? Una síntesis jurisprudencial del Tribunal Constitucional de Chile", en El diálogo transjudicial de los Tribunales Constitucionales entre sí y con las Cortes Internacionales de Derechos Humanos, coord. Humberto Nogueira (Santiago: Librotecnia, 2012), 263. 
inconsistencia, que se deriva por la posibilidad de que el TC al inaplicar una norma de un tratado internacional puede, eventualmente, incurrir en responsabilidad internacional ${ }^{8}$. Así en primer lugar, nos haremos cargo de la tesis asumida en el rol 2789 y su inconstitucionalidad, para finalizar con la corrección de la primitiva postura de la magistratura constitucional generando una tesis conforme a la Constitución y al Derecho Internacional Público.

\subsection{La inconstitucional interpretación del art. 54.1}

\subsubsection{La naturaleza de los tratados internacionales y su vigencia en el ámbito internacional e interno}

Los tratados internacionales no son una ley. Su origen es convencional y deriva del derecho internacional. Son definidos por Benadava como "acuerdo celebrado entre dos o más estados, regido por el derecho internacional y destinado a producir efectos jurídicos". $\mathrm{El}$ tratado es una fuente del derecho internacional y ahí es donde despliega todos sus efectos jurídicos.

Respecto de cómo un tratado adquiere vigencia en el orden interno de los Estados, es importante recordar lo señalado por Ximena Fuentes: “(...) No existe todavía ninguna norma internacional general que disponga cómo los respectivos Estados deben incorporar el derecho internacional en los sistemas juridicos domésticos. De hecho, ni siquiera existe la obligación general de hacer que el derecho internacional ingrese al derecho interno". ${ }^{10}$

\subsection{2. ¿Qué significa entonces el art. 54.1 de la Constitución?}

El ya repetido art. 54.1 lo que hace es constitucionalizar una norma general del derecho internacional, aquella contenida en el art. 27 de la Convención de Viena sobre el Derecho de los Tratados ${ }^{11}$, y que tiene por objeto que todo tratado produzca sus efectos jurídicos en

8 Se dice eventualmente, pues como señala Gastón Gómez la inaplicabilidad funciona "como control de interpretaciones o significados de los enunciados (normas) aplicables a casos. Si bien lo que se declara inaplicable por inconstitucional - ineficaz. circunstancialmente - a un caso concreto es formalmente el enunciado legal, en realidad, es la o las interpretaciones o significados de ese enunciado que el juezo la parte consideran inconstitucionales en la especifica aplicación de dicha norma al caso". En este entendido, no siempre la inaplicabilidad tendrá como resultado la vulneración de una obligación internacional, pues puede el Tribunal Constitucional intentar buscar una interpretación del precepto legal contenido en un tratado internacional de conformidad a las obligaciones internacionales que emanan de éste, tal como ha esbozado en el Rol 804 donde ha señalado: "Que, indudablemente, el intérprete en general y el juez en particular debe realizar los mayores esfuerzos, dentro del ámbito constitucional, para procurar cumplir de buena fe las disposiciones y fines del tratado, conciliando sus disposiciones con otras normas del Derecho Interno, prefiriendo aquellas interpretaciones que armonicen los derechos y obligaciones que del tratado internacional se derivan con el orden jurídico chileno". Es decir, una interpretación conciliatoria.

9 Santiago Benadava, Derecho Internacional Público, 8a ed. (Santiago: LexisNexis, 2004), 23. La Convención de Viena sobre Derecho de los Tratados los define en su art. 2 como: “(...) un acuerdo internacional celebrado por escrito entre Estados y regido por el derecho internacional, ya conste en un instrumento único o en dos o más instrumentos conexos y cualquiera que sea su denominación particular".

10 En el mismo sentido: José Pastor, Curso de Derecho Internacional Público y Organizaciones Internacionales, 9a ed. (Madrid: Tecnos, 2003), 169. Ximena Fuentes, "El derecho internacional y el derecho interno: definitivamente una pareja dispareja", Revista de Derecho y Economía 16(4) (2007).

11 Artículo 27.- El derecho interno y la observancia de los tratados una parte no podrá invocar las disposiciones de su derecho interno como justificación del incumplimiento de un tratado. esta norma se entenderá sin perjuicio de lo dispuesto en el artículo 46. 
el ámbito internacional, no pudiendo el Estado eludir responsabilidad alegando una norma interna que lo excuse. ${ }^{12}$

Así las cosas, lo que implica la mencionada disposición constitucional es que el derecho interno no puede afectar el tratado en cuanto a su vigencia internacional.

\subsection{La procedencia de la acción de inaplicabilidad respecto de los tratados internacionales vigentes en el orden jurídico interno y la posibilidad de responsabilidad internacional}

Luego de todo lo señalado, es preciso señalar que los Tratados Internacionales tienen un origen en el derecho internacional y en él produce sus efectos. Nuestro ordenamiento jurídico, siguiendo el análisis que hace de la Constitución Española Pastor Ridruejo, establece un dualismo racional. Desde esa perspectiva y lo razonado hasta ahora. En cuanto a validez y vigencia interna los tratados internacionales se someten a la Constitución.

Pero se debe tener en claro que la declaratoria de inaplicabilidad no deroga, ni modifica, ni suspende un tratado internacional en el orden jurídico internacional, no contradice el art. 54. 1 de la Constitución, ni el art. 27 de la Convención de Viena. Y la manifestación más clara de ello, es la posibilidad de incurrir en un acto internacionalmente ilícito, y por tanto, irrogar responsabilidad internacional.

Siendo coherente con lo anterior, la inaplicabilidad de un tratado no procede siempre, sino solamente en cuanto se encuentre vigente en el ordenamiento jurídico Chileno, lo que no se produce por la mera ratificación, como ha sostenido el Tribunal Constitucional, sino que como ha señalado Aldunate y Llanos Mansilla, desde que el tratado se encuentra promulgado y publicado, situación que es concordante con la práctica jurisprudencial y la normativa chilena.

\section{Conclusiones}

Ante el derecho internacional el derecho interno, incluida su Constitución, es sólo un hecho. Asimismo todo el Estado es un ente unitario frente a la responsabilidad internacional. Pero como hemos señalado una cosa son los efectos del Tratado internacional como fuente de obligaciones internacionales, y otra su validez y vigencia en el orden jurídico Chileno. Por todo lo anteriormente expuesto, es perfectamente posible, conforme a la reglas constitucionales declarar inaplicable un tratado internacional vigente

12 Principio que no es absoluto, como se desprende del art. 46 de la misma Convención de Viena sobre Derecho de los Tratados. 
Revista Tribuna Internacional

Volumen $5 \bullet \mathrm{N}^{\circ}$ 9 $・ 2016 \bullet$ pp. 155-161

ISSN 0719-482X (versión en línea)

en Chile, teniendo presente que tal declaratoria, reafirma la supremacía constitucional y, eventualmente, podría hacer incurrir al Estado en responsabilidad internacional. Pudiendo concluir de los hasta aquí razonado que:

1. Los tratados internacionales durante su vigencia en el orden jurídico chileno son preceptos legales objeto del recurso de inaplicabilidad.

2. Conforme al sistema constitucional chileno, frente a los efectos inconstitucionales de la aplicación de un tratado internacional (vigente en el orden interno) debe declararse la inaplicabilidad, ello sin perjuicio de la necesaria interpretación conciliatoria.

3. Declarada la inaplicabilidad, eventualmente, y no en todos los casos, se puede incurrir en responsabilidad internacional del Estado.

4. Lo señalado hasta ahora, en principio, no aplica a las disposiciones de tratados internacionales que contengan derechos que emanan de la esencia de la naturaleza humana, donde ni la doctrina, ni jurisprudencia constitucional ${ }^{13}$ son pacíficas respecto a su tratamiento.

13 Así lo deja ver la Profesora Galdámez al referirse a la inconsistencia del Tribunal Constitucional sobre esta especifica materia: "En efecto, si en 1987 la tesis del Tribunal Constitucional era coherente con su propia jurisprudencia, no ocurre lo mismo en 2013 cuando se han dictado ya un conjunto de sentencias que desarrollan la noción de derechos esenciales que emanan de la naturaleza bumana como una categoría que supone apertura constitucional en el catálogo de derechos". Liliana Galdámez, "Comentario jurisprudencial: La consulta a los pueblos indígenas en la sentencia del Tribunal Constitucional sobre ley de pesca roles Nos. 2387-12 CPT y 2388-12 CPT, acumulados", Estudios Constitucionales, 11(1) (2013): 624. 